\title{
BMJ open Comparison of screening strategies to improve the diagnosis of latent tuberculosis infection in the HIV- positive population: a cohort study
}

\author{
Katrina M Pollock, ${ }^{1}$ Herman Tam, ${ }^{1}$ Lisa Grass, ${ }^{1}$ Sharleen Bowes, ${ }^{1}$ \\ Graham S Cooke, ${ }^{2}$ Manish Pareek, ${ }^{1}$ Damien Montamat-Sicotte, ${ }^{1}$ \\ Moses Kapembwa, ${ }^{3}$ Graham P Taylor, ${ }^{2}$ Ajit Lalvani ${ }^{1}$
}

To cite: Pollock KM, Tam H, Grass L, et al. Comparison of screening strategies to improve the diagnosis of latent tuberculosis infection in the HIV-positive population: a cohort study. BMJ Open 2012;2:e000762. doi:10.1136/

bmjopen-2011-000762

- Prepublication history for this paper is available online. To view these files please visit the journal online (http:// dx.doi.org/10.1136/ bmjopen-2011-000762)

Received 14 December 2011 Accepted 23 January 2012

This final article is available for use under the terms of the Creative Commons Attribution Non-Commercial 2.0 Licence; see http://bmjopen.bmj.com

${ }^{1}$ Tuberculosis Research Unit, National Heart and Lung Institute, Imperial College London, London, UK ${ }^{2}$ Section of Infectious Diseases, Department of Medicine, Imperial College London, London, UK

${ }^{3}$ Department of Genitourinary and HIV medicine, Northwick Park Hospital, The North West London Hospitals NHS Trust, Middlesex, UK

Correspondence to Dr Katrina Mary Pollock; k.pollock@imperial.ac.uk

\section{ABSTRACT}

Background: HIV is the most important risk factor for progression of latent tuberculosis infection (LTBI) to active tuberculosis (TB). Detection and treatment of $L T B I$ is necessary to reduce the increasing burden of TB in the UK, but a unified LTBI screening approach has not been adopted.

Objective: To compare the effectiveness of a TB riskfocused approach to LTBI screening in the HIV-positive population against current UK National Institute for Health and Clinical Excellence (NICE) guidance.

Design: Prospective cohort study.

Setting: Two urban HIV treatment centres in London, UK.

Participants: 114 HIV-infected individuals with defined TB risk factors were enrolled prospectively as part of ongoing studies into HIV and TB co-infection. Outcome measures: The yield and case detection rate of LTBI cases within the research study were compared with those generated by the NICE criteria. Results: $17 / 114$ (14.9\%, 95\% Cl 8.3 to 21.5$)$ had evidence of LTBI. Limiting screening to those meeting NICE criteria for the general population $(n=43)$ would have detected just over half of these, $9 / 43(20.9 \%$, $95 \% \mathrm{Cl} 8.3$ to 33.5 ) and those meeting criteria for HIV co-infection $(\mathrm{n}=74)$ would only have captured $8 / 74$ (10.8\%, $95 \% \mathrm{Cl} 3.6$ to 18.1$)$ cases. The case detection rates from the study and NICE approaches were not significantly different. LTBI was associated with the presence of multiple TB risk factors $(p=0.002)$.

Conclusion: Adoption of a TB risk-focused screening algorithm that does not use CD4 count stratification could prevent more cases of TB reactivation, without changing the case detection rate. These findings should be used to inform a large-scale study to create unified guidelines.

\section{INTRODUCTION}

The incidence of disease caused by Mycobacterium tuberculosis (MTB) infection in the UK has increased over the past 20 years and there were 8483 notifications of tuberculosis (TB)

\section{ARTICLE SUMMARY}

Article focus

- HIV is the single most important risk factor for the progression of LTBI to active TB.

- Despite this, the UK approach to screening for LTBI in HIV co-infected individuals is not unified as the evidence base is insufficient.

n We hypothesised that LTBI screening in HIV coinfected individuals required an approach focused on TB risk factors that was broader than recommended by NICE.

\section{Key messages}

- Screening strategies for LTBI in HIV co-infected patients that focus on limited TB risk factors (recent entrance from a TB endemic area or history of TB contact) or limit screening to those with a CD4 count of $\leq 500$ cells/ $\mu$ l would detect approximately half the total cases in this cohort.

- A TB risk-focused approach could aid in the prevention of more cases of active TB and HIV co-infection.

Strengths and limitations of this study

n This study addresses the utility of NICE guidance for LTBI screening in the HIV co-infected population.

- Numbers were relatively small, therefore a large study is needed to better inform UK guidance on LTBI screening in the HIV co-infected population.

in $2010 .{ }^{1}$ Co-infection with HIV was found in $4.9 \%$ of UK active TB cases in $2010,{ }^{1}$ and the total number of co-infection cases has increased year on year in the European region, from 9200 in 2007 to 13821 in $2009 .{ }^{2}$ The prevention of co-infection cases rests in part on treating latent tuberculosis infection (LTBI); however, there is little empiric evidence guiding LTBI screening in the HIV-positive population.

Treatment of LTBI reduces the risk of progression to active $\mathrm{TB},{ }^{3}$ which in the 
setting of HIV co-infection is more severe and associated with extrapulmonary disease ${ }^{4-6}$ and reduces the risk of onward transmission and infection. ${ }^{7}$ The complex pharmacological interactions, risk of immune reconstitution inflammatory syndrome and considerable pill burden consequent upon treating both infections contemporaneously are thus avoided. Preventing active TB has potential cost savings; active TB treatment costs $£ 7095.08$ more than 6 months of isoniazid therapy. ${ }^{8}$

It is unknown whether the criteria for LTBI screening should be the same as in the general population or whether they should be tailored to the needs of the HIVinfected. Recently published National Institute for Health and Clinical Excellence (NICE) guidance $^{9}$ recommends that testing should be carried out in all contacts of active TB and new entrants from high incidence countries for the general population and the use of single- or dual-step screening based on CD4 count for the immunosuppressed. We postulated that the target HIV-infected population for LTBI screening should be broader because of the wealth of data demonstrating the resurgence of TB due to the HIV epidemic. ${ }^{10}{ }^{11} \mathrm{HIV}$ is the single most important risk factor for progression of LTBI to active disease and the risk of active TB increases with immunosuppression ${ }^{12} 13$ and is associated with MTB infection and re-infection. ${ }^{14}$ Therefore, an effective screening strategy to detect and treat LTBI in those most likely to become infected and to progress to active disease is of public health interest.

Concerns regarding the sensitivity of both the tuberculin skin test (TST) and interferon- $\gamma$ (IFN- $\gamma$ ) release assays (IGRAs) in the HIV-infected population have hindered their widespread use in HIV co-infection. The TST has poor sensitivity in HIV-infected patients ${ }^{15}$ and poor specificity in those who have been BCG vaccinated $^{16}$ or those with a non-tuberculous mycobacterial infection. It is a well-characterised assay, however, which can improve targeting of chemoprophylaxis to those most likely to benefit. ${ }^{17}$ New HIV guidelines suggest using IGRAs rather than TST for LTBI screening, ${ }^{18}$ and NICE recommends IGRAs, with or without TST, dependent on CD4 count. ${ }^{9}$ IGRAs use the antigenic targets, ESAT-6 and CFP-10, which are absent from BCG, improving sensitivity and specificity for the diagnosis of MTB infection. ${ }^{16} 19$ There is some evidence that the ELISpot platform is more sensitive in the setting of HIV than the TST, ${ }^{19}{ }^{20}$ but more data are needed.

Current clinical practice for LTBI screening in the HIV population is not uniform. Some units, as exemplified by the two large HIV clinics studied, screen a broader target population for LTBI than the NICE criteria because of the increased risk of active TB. Since this approach is not based on empiric evidence, we examined the yield and case detection rate of LTBI cases using both the criteria recommended by NICE and by our broader research study criteria. To our knowledge, this is the first work to specifically address the effectiveness of the NICE criteria in the HIV-positive population.

\section{METHODS}

Subjects with HIV infection were prescreened by notes review for LTBI risk factors and recruited from two London HIV clinics (Imperial College Healthcare NHS Trust and Northwest London Hospitals NHS Trust) during January 2008-December 2010 as part of ongoing studies into HIV and MTB co-infection. Radiological findings, TST results and demographic data were collected. A cut-off of $\geq 5 \mathrm{~mm}$ was used for TST positivity. ${ }^{17}{ }^{21}$ Patients with clinical (cough, fever, night sweats, haemoptysis, weight loss), radiological or microbiological evidence of active TB and those with a history of TB treatment or chemoprophylaxis were excluded. Data on risk factors for TB were systematically recorded as part of the parent study. A history of TB contact at any time (recent or remote) was recorded.

Box 1 summarises current UK guidance for LTBI screening in HIV.

Box 1 UK guidance for latent tuberculosis infection (LTBI) screening with reference to HIV co-infection

National Institute for Health and Clinical Excellence guidance on LTBI diagnosis ${ }^{9}$

1. Tuberculosis (TB) contacts

Offer Mantoux testing in line with the Green Book to diagnose latent TB in people who are:

- household contacts (aged 5 years and older) of all people with active TB.

- non-household contacts (other close contacts, eg, in workplaces and schools).

Consider interferon- $\gamma$ testing for people whose Mantoux testing shows positive results or in people for whom Mantoux testing may be less reliable, eg, BCG-vaccinated people.

If Mantoux testing is inconclusive, refer the person to a TB specialist.

2. New entrants from high-incidence countries

Offer either an interferon- $\gamma$ test alone or a dual strategy in people aged $16-35$ years. For people aged 35 years or older, consider the individual risks and benefits of likely subsequent treatment, before offering testing.

3. Immunocompromised

For people with HIV and CD4 counts less than 200 cells $/ \mu$, offer an interferon- $\gamma$ test and a concurrent Mantoux test. If either test is positive: perform a clinical assessment to exclude active TB and consider treating latent TB infection. For people with HIV and CD4 counts of $200-500$ cells/ $\mu \mathrm{l}$, offer an interferon- $\gamma$ test alone or an interferon- $\gamma$ test with a concurrent Mantoux test. If either test is positive: perform a clinical assessment to exclude active TB and consider treating latent TB infection.

BHIVA 2011 guidelines $^{18}$

Consider country of origin, CD4 count and length of time on highly active antiretroviral therapy. Close contacts of infectious TB should be offered chemoprophylaxis. Interferon- $\gamma$ release assays rather than tuberculin skin test are recommended, although there is a call for more data. 


\section{UK guidance (NICE guidelines)}

NICE recommends screening TB contacts and new entrants ( $\leq 5$ years) from high $\mathrm{TB}$ incidence countries (estimated incidence rate of 40/100000) ${ }^{9}$ in those aged 16-35 years and to consider the risks and benefits of treatment before offering testing to those aged 35 years or older. People with HIV who are in close contact with people with sputum smear-positive respiratory TB should have active disease excluded and then be given treatment for latent TB infection. Treatment of LTBI should be for people of any age who have HIV; therefore, an upper age limit for LTBI screening was not imposed in this study. Screening for immunosuppressed is recommended as a dual step (IGRA and TST) for those with a CD4 count $<200$ cells $/ \mu$ and as single or dual step for those with a CD4 count 200-500 cells/ $\mu$ l.

\section{Research study screening approach}

HIV-positive participants were classified as at risk of LTBI according to a set of TB risk criteria. Those included had a history of TB contact and/or were migrants from a TB endemic country, regardless of date of entry into the UK or had two or more additional risk factors (see table 1 for empirical evidence on TB risk factors): travel to a TB endemic area, smoking, more than occasional alcohol intake, homelessness, injecting drug use, prison stay or healthcare work.

\section{Diagnosis of LTBI}

All participants were screened with the research study IGRA, an in-house IFN- $\gamma$ MTB ELISpot. Evidence of an immunological response (positive IFN- $\gamma$ secretion) to TB was made using the MTB region of difference-1 (RD-1) antigens, ESAT-6 and CFP-10, which are present in the commercial T-Spot ${ }^{\circledR} . T B$ assay, and thus, the results generated were considered to be equivalent to those generated by the commercial assay. The test was performed using pools of overlapping 15-mer peptides, as described previously. ${ }^{36} \mathrm{~A}$ positive response was defined as at least five spot-forming cells more than the negative control well and at least twice the negative control well. Where participants had been screened as part of routine clinical work, this result was also used to define cases of LTBI. The commercial IGRAs, T-Spot ${ }^{\circledR} . T B$ or QuantiFERON ${ }^{\circledR}$-TB Gold-In Tube (QFT), were performed by the clinical diagnostic laboratory. TST data were available for 20 cases but TST was not routinely performed in accordance with BHIVA guidance. We defined LTBI as a positive response in any of the screening assays (IGRA or TST).

Statistical analysis was performed using SPSS ${ }^{\circledR}$ Statistics (IBM ${ }^{\circledR)}$ V.20 and Prism 5 GraphPad Software, Inc, (La Jolla, California, USA). A Fisher's exact test was used to compare proportions. Significance was assessed at the $5 \%$ and $1 \%$ level.

\section{RESULTS}

\section{Research study screening approach}

A total of 114 HIV-positive individuals were identified as at risk of LTBI according to the study protocol. Median age was 39 years (IQR 31.0-44.0), $77(67.5 \%)$ were from

Table 1 Evidence for risk factors used in the study

\begin{tabular}{|c|c|}
\hline Risk factor & Evidence \\
\hline Born in a TB endemic area & $\begin{array}{l}\text { HR for TB recurrence for foreign born } 3.2(95 \% \mathrm{Cl} 1.2 \text { to } 9.0)^{22} \\
\text { Adjusted OR for TST positivity for LTBI in students } 43.5(95 \% \mathrm{Cl} 25.2 \text { to } 72.3)^{23}\end{array}$ \\
\hline Residence in a TB endemic area & OR for QFT positivity in HIV patients $5.7(95 \% \mathrm{Cl} 2.6 \text { to } 12.5)^{24}$ \\
\hline TB contact & $\begin{array}{l}\text { OR for QFT positivity in HIV patients } 4.9(95 \% \mathrm{Cl} 2.0 \text { to } 11.8)^{24} \\
\text { OR for QFT positivity in HIV patients } 7.8(\mathrm{p}=0.023)^{25}\end{array}$ \\
\hline Alcohol & $\begin{array}{l}\text { HR for incident TB in men drinking } 50-99 \mathrm{~g} \text { alcohol per day } 1.2(95 \% \mathrm{Cl} 1.1 \text { to } 1.3) \\
\text { and } \geq 100 \mathrm{~g} \text { alcohol per day } 1.5(95 \% \mathrm{Cl} 1.3 \text { to } 1.7)^{26}\end{array}$ \\
\hline Smoking & $\begin{array}{l}\text { HR for TB mortality in current male smokers } 1.6(95 \% \mathrm{Cl} 1.3 \text { to } 2.0) \text { and incident } \\
\text { TB current male smokers } 1.4(95 \% \mathrm{Cl} 1.3 \text { to } 1.5)^{26}\end{array}$ \\
\hline & $\begin{array}{l}\text { Smoking associated with TB (weighted } \mathrm{OR} 2.4,95 \% \mathrm{Cl} 1.71 \text { to } 3.39, \mathrm{p}<0.001 \text { ) and } \\
\text { a worse clinical picture, e.g., cavitation (OR } 1.76,95 \% \mathrm{Cl} 1.18 \text { to } 2.63)^{27} \\
\text { Smoking associated with pulmonary TB (adjusted } \mathrm{HR} 2.87,95 \% \mathrm{Cl} 2.00 \text { to } 4.11)^{28} \\
\text { Pulmonary TB associated with smoking aOR }(1.5)^{29}\end{array}$ \\
\hline Healthcare work & $\begin{array}{l}\text { TST conversion associated with nursing and ethnicity }{ }^{30} \\
\text { TST conversion associated with place of healthcare work, e.g., infectious diseases } \\
\text { HR } 1.94(95 \% \mathrm{Cl} 1.50 \text { to } 2.49) \text { in multivariate analysis }{ }^{31} \\
\text { Risk of TB higher for healthcare workers than the general population }{ }^{32}\end{array}$ \\
\hline Illicit drug use & $\begin{array}{l}\text { Higher rates of TST positivity in crack smokers }{ }^{33} \\
\text { HR for TB recurrence } 2.9(95 \% \mathrm{Cl} 1.3 \text { to } 6.4)^{22} \\
\text { OR for QFT positivity in HIV patients } 9.8(\mathrm{p}=0.031)^{25}\end{array}$ \\
\hline Period of homelessness & OR for QFT positivity in HIV patients $5.2(p=0.018)^{25}$ \\
\hline Prison & $\begin{array}{l}\text { High prevalence of active TB in prisons in sub-Saharan Africa } \\
\text { Incidence rate ratio for LTBI } 26.4 \text { (IQR 13.0-61.8) and TB } 23.0\left(\text { IQR 11.7-36.1) }{ }^{35}\right.\end{array}$ \\
\hline Multiple risk factors & OR in HIV patients for one or more risk factors $7.2(2.9-18.2)^{24}$ \\
\hline
\end{tabular}


sub-Saharan Africa and 11 (9.6\%) were from central and southern America (table 2). The median (IQR) CD4 count was $412(310-628)$ cells $/ \mu \mathrm{l}$ and $72(63.2 \%)$ were prescribed highly active antiretroviral therapy (HAART) at time of recruitment, $64(56.1 \%)$ were women and 50 $(43.9 \%)$ were men. Seventeen of $114(14.9 \%, 95 \%$ CI 8.3 to 21.5) participants were diagnosed with LTBI in total. Results of IGRA and TST are presented in table 3. The local LTBI screening protocol detected nine $(52.9 \%$, $95 \%$ CI 26.5 to 79.3 ) cases and one had a negative screen (TST and IGRA) in the clinic but a positive study IGRA. Seven individuals $(41.2 \%$, 95\% CI 15.1 to 67.3$)$ who had not been referred for clinical screening had a positive research study IGRA. Therefore, the research study approach increased the number of individuals diagnosed with LTBI compared with current clinical services, with an overall case detection rate of $14.9 \%$ (table 4).

Table 2 Demographic characteristics of participants eligible for LTBI screening

\begin{tabular}{|c|c|c|}
\hline Demographic & $\mathrm{N}=114$ & $\%$ \\
\hline \multicolumn{3}{|l|}{ Age (years) } \\
\hline$\leq 25$ & 12 & 10.5 \\
\hline $26-35$ & 32 & 28.1 \\
\hline $36+$ & 70 & 61.4 \\
\hline \multicolumn{3}{|l|}{ Sex } \\
\hline Female & 64 & 56.1 \\
\hline Male & 50 & 43.9 \\
\hline \multicolumn{3}{|l|}{ Origin } \\
\hline $\begin{array}{l}\text { Europe, North America, } \\
\text { Caribbean, Australia }\end{array}$ & 13 & 11.4 \\
\hline Middle East, North Africa & 2 & 1.8 \\
\hline Other Asia & 8 & 7.0 \\
\hline Indian Subcontinent & 3 & 2.6 \\
\hline Sub-Saharan Africa & 77 & 67.5 \\
\hline Central and Southern America & 11 & 9.6 \\
\hline \multicolumn{3}{|l|}{$B C G$ vaccinated } \\
\hline Yes & 87 & 76.3 \\
\hline No & 9 & 7.9 \\
\hline Unknown & 18 & 15.8 \\
\hline \multicolumn{3}{|l|}{ TST (mm) } \\
\hline$\geq 5$ & 6 & 5.3 \\
\hline$<5$ & 14 & 12.2 \\
\hline Not done & 94 & 82.5 \\
\hline \multicolumn{3}{|l|}{ CD4 count } \\
\hline $0-199$ & 14 & 12.3 \\
\hline $200-500$ & 60 & 52.6 \\
\hline$>500$ & 40 & 35.1 \\
\hline \multicolumn{3}{|l|}{ Viral load } \\
\hline$<50$ & 49 & 43.0 \\
\hline $50-1000$ & 24 & 21.1 \\
\hline$>1000$ & 41 & 36.0 \\
\hline \multicolumn{3}{|l|}{ HAART therapy } \\
\hline Yes & 72 & 63.2 \\
\hline No & 42 & 36.8 \\
\hline
\end{tabular}

Table 3 IGRA (commercial or research assay) and TST results

\begin{tabular}{llll}
\hline & $\begin{array}{l}\text { Positive } \\
\text { IGRA }\end{array}$ & $\begin{array}{l}\text { Positive } \\
\text { TST }\end{array}$ & $\begin{array}{l}\text { Total positive in } \\
\text { either or both } \\
\text { tests }\end{array}$ \\
\hline $\begin{array}{l}\text { IGRA only } \\
\text { TST and }\end{array}$ & $10 / 94$ & NA & $10 / 94(10.6 \%)$ \\
IGRA & $6 / 20$ & $6 / 20$ & $7 / 20^{*}(35.0 \%)$ \\
\hline
\end{tabular}

*All participants underwent research IGRA screening, of the 20 participants who also underwent TST, discordance occurred in two cases (one was positive who had a negative IGRA result and one was negative who had positive IGRA result).

IGRA, interferon- $\gamma$ release assay; NA, not applicable; TST, tuberculin skin test.

\section{NICE guidance approach}

A smaller proportion would have fulfilled NICE guidance criteria for the general population (recent migrant from a TB endemic area or TB contact). Screening according to NICE guidance would have meant that 43/ $114(37.7 \%$, 95\% CI 28.6 to 46.8$)$ would have been eligible for screening of whom, 9/43 (20.9\%, 95\% CI 8.3 to 33.5 ) would have been diagnosed with LTBI (table 4). The remaining $71(62.3 \%, 95 \%$ CI 53.2 to 71.3$)$ would not be screened according to NICE guidance and 8/17 $(47.1 \%, 95 \%$ CI 20.6 to 73.5$)$ with LTBI would remain undiagnosed. The detection rate was not significantly higher than with the research study approach $(p=0.470)$, and the diagnostic yield was only $52.9 \%$ of all LTBI cases detected.

When examining the criteria specifically for immunosuppressed patients suggested by NICE, 14/114 (12.3\%, $95 \%$ CI 6.2 to 18.3 ) had a CD4 count of $<200$ cells $/ \mu 1$ and would have been eligible for dual-step screening and $60 / 114(52.6 \%, 95 \%$ CI 43.3 to 61.9$)$ had a CD4 count of $200-500$ cells $/ \mu \mathrm{l}$ and would have been eligible for single- or dual-step screening. A remaining 40/114 $(35.1 \%, 95 \%$ CI 26.1 to 43.4$)$ had a CD4 count of greater than 500 cells $/ \mu$ l and would not have been recommended either approach. Of those with LTBI, none had a CD4 count of $<200$ cells $/ \mu \mathrm{l}, 8 / 17(47.1 \%, 95 \%$ CI 21.6 to 73.5) had a CD4 count of $200-500$ cells/ $\mu \mathrm{l}$ and $9 / 17$ $(52.9 \%, 95 \%$ CI 26.5 to 79.3$)$ had a CD4 count of $>500$ cells $/ \mu \mathrm{l}$. Therefore, using this approach, fewer than half the LTBI cases would have been detected, and the detection rate would have fallen to $8 / 74(10.8 \%$, 95\% CI 3.6 to 18.1), although this was not different from the study approach $(\mathrm{p}=0.512)$.

\section{Risk factors for LTBI}

A full TB risk history was taken at the time of recruitment to the study. The TB risk factors used for selection of subjects were chosen based on the available evidence (table 1). On univariate analysis, more than occasional alcohol intake $(p=0.008)$, injecting drug use $(p=0.023)$ and two or more $(\mathrm{p}=0.011)$ or three or more TB risk factors $(\mathrm{p}=0.002)$ were associated with LTBI (table 5). A history of recent or remote TB contact or a history of 
Table 4 Case detection rates for latent tuberculosis infection (defined as positive TST and/or IGRA) for different screening strategies

\begin{tabular}{lllll}
\hline Screening approach & Number tested & Number positive & $\begin{array}{l}\text { Case detection } \\
\text { rate (\%) }\end{array}$ & $\begin{array}{l}\text { Proportion of latent TB } \\
\text { infection identified (\%) }\end{array}$ \\
\hline Study & 114 & 17 & 14.9 & 100.0 \\
NICE general population & 43 & 9 & 20.9 & 52.9 \\
NICE immunosuppressed & 74 & 8 & 10.8 & 47.1 \\
\hline IGRA, interferon- $\gamma$ release assay; NICE, National Institute for Health and Clinical Excellence; TST, tuberculin skin test.
\end{tabular}

immigration from a TB endemic area within 5 years was not associated with LTBI. Multivariate analysis was not performed as numbers were small. The presence of multiple, rather than specific, TB risk factors was therefore most strongly associated with LTBI in this cohort.

\section{DISCUSSION}

The study has demonstrated that using currently available tools, a structured approach to screening in the HIV-positive population detects LTBI in one in seven of those with TB risk factors. Screening according to NICE guidance using either general population guidance or that specifically suggested for immunosuppressed individuals would only have detected half or fewer of these LTBI cases. This is an important finding given that recently published BHIVA guidance also recommends screening stratified by CD4 count.

The case detection rate from the study approach was not significantly different from the rates generated by the NICE approach. The number needed-to-be screened increased, however, from 43 with NICE-specified risk factors for the general population to 114. Although this represents a 2.7-fold increase, which carries a cost implication, this would place a minimal additional strain on resources. However, if NICE screening stratified by CD4 count were adopted, a total of 74 cases would have been eligible for single- or dual-step screening. The estimated costs of each test are: TST (£16.14); T-Spot ${ }^{\circledR} . T B(£ 55)$ and QFT $(£ 45)^{8}$. In this study, the estimated additional cost of screening those who did not fulfil NICE criteria for immunosuppressed individuals $(n=40)$ would have been $£ 2200$ for T-Spot ${ }^{\circledR}$.TB alone and $£ 2845.60$ for a dual TST and T-Spot ${ }^{\circledR}$.TB screening strategy. These costs, in addition to the cost of chemoprophylaxis (estimated at $£ 524.59$, range $£ 262.30-£ 1049.18$ for 6 months Isoni$\operatorname{azid}^{8}$ ), are small compared with the cost of treating one case of active TB/HIV co-infection, where treatment of TB alone has been estimated at $£ 7619.67$ (range $£ 3809.84-£ 15239.34)$. $^{8}$

Recent work has suggested that a single-step IGRA approach is cost effective, ${ }^{9}$ as is screening in the immigrant population. ${ }^{37}$ In our study, TST was positive in one individual with a negative IGRA. The increased risk of both progression and expensive-to-treat extrapulmonary or invasive disease in the HIV population would therefore be expected to improve the incremental cost-effectiveness ratios and thus increase the cost-effectiveness of screening for LTBI. In other clinical HIV cohorts, where there is a higher proportion of sub-Saharan Africans (in whom the prevalence of LTBI is highest), screening would also be more cost effective. A full cost-effectiveness analysis is required to determine whether single- or dual-step testing would be most appropriate in this population.

Table 5 Comparison of risk factors for latent TB infection from those used in the study screening approach

\begin{tabular}{|c|c|c|c|c|c|}
\hline \multirow[b]{2}{*}{ TB risk factor } & \multicolumn{2}{|c|}{$\begin{array}{l}\text { Diagnosed with } \\
\text { latent TB infection }\end{array}$} & \multicolumn{2}{|c|}{$\begin{array}{l}\text { No latent TB } \\
\text { infection }\end{array}$} & \multirow[b]{2}{*}{$\mathbf{p}^{\mathbf{a}}$} \\
\hline & $\mathbf{n}=$ & & $\mathrm{n}=$ & & \\
\hline Born in a TB endemic country & 15 & 88.2 & 83 & 85.6 & NS \\
\hline New entrant & 4 & 23.5 & 13 & 13.4 & NS \\
\hline TB contact & 5 & 29.4 & 23 & 23.7 & NS \\
\hline Travel to a TB endemic area & 11 & 64.7 & 45 & 46.4 & NS \\
\hline Alcohol & 7 & 41.2 & 12 & 12.4 & $0.008^{*}$ \\
\hline Smoking & 6 & 35.3 & 22 & 22.7 & NS \\
\hline Healthcare work & 3 & 17.6 & 8 & 8.2 & NS \\
\hline Injecting drug use & 3 & 17.6 & 2 & 2.1 & $0.023 \dagger$ \\
\hline Period of homelessness & 1 & 5.9 & 4 & 4.1 & NS \\
\hline Prison & 2 & 11.8 & 3 & 3.1 & NS \\
\hline$\geq 2$ risk factors & 17 & 100.0 & 69 & 71.1 & $0.011 \dagger$ \\
\hline$\geq 3$ risk factors & 13 & 76.5 & 34 & 35.1 & $0.002^{*}$ \\
\hline
\end{tabular}


Extrapolating the study results to the wider UK setting, in 2010, there were 23714 black Africans older than 14 years accessing care for HIV in the UK. ${ }^{38}$ If we assume $14.9 \%$ (95\% CI 8.3 to 21.5 ) would have LTBI (3533.4 cases), then approximately half would be diagnosed according to the NICE criteria for either the general or immunosuppressed population and 1766.7 cases would remain undiagnosed. Estimates of those at risk of developing active TB vary and include data from the preHAART era; estimates of $5 \%-8 \%$ in 1 year have been suggested, ${ }^{3}{ }^{39}$ which would mean $88.3-141.3$ at risk of developing active $\mathrm{TB}$ in the subsequent 12 months. Clinical observation in the HAART era suggests that this estimate may be too high. Long-term observational data are required to quantify this and to add to the limited available evidence for the prognostic power of IGRAs. ${ }^{40}$

The presence of multiple risk factors, rather than particular risk factors, was most highly associated with LTBI in our cohort. Since all patients with LTBI had two or more risk factors, there is potential to reduce the numbers screened by 25\%. Studies in HIV-infected populations have been carried out in Europe; in Spain, ${ }^{41}$ Germany $^{42}$ and Denmark, ${ }^{24}$ rates of IGRA positivity of $6.7 \%-9.3 \%, 18.9 \%-24 \%$ and $4.6 \%$, respectively, were found. Brock et $a l^{24}$ showed that previous TB diagnosis, history of exposure, long-term residence in a TB endemic country and the presence of one risk factor or more were associated with a positive QFN. Active TB was associated with black African ethnicity, low CD4 count and a shorter time on HAART in a UK study. ${ }^{43}$

The diagnostic ability of the different assay platforms has been previously studied. ${ }^{19}{ }^{44-46}$ There is evidence to suggest that the ELISpot platform retains sensitivity in HIV-infected individuals, ${ }^{44}{ }^{47-49}$ but there is no gold standard test for LTBI and all methods may be affected by HIV-induced immunosuppression. Despite this, the use of the ELISpot platform in our study detected a significant rate of undiagnosed LTBI.

A pragmatic approach to screening for LTBI in HIV co-infection is both necessary and possible. Screening recent immigrants from endemic countries and TB contacts would identify just over half of all cases and can be recommended only as a minimum. Screening by stratification of CD4 count would also only detect less than half the cases. Expanding the screening criteria to include multiple risk factors, which would, using currently available assays double the yield without altering the case detection rate, should be considered as an alternative strategy.

Acknowledgements Dr Lee Potiphar, Mr Samuel Bremang, the staff at the Jefferiss Wing Clinic, St Mary's Hospital, London and Northwick Park Hospital Genitourinary and HIV Medicine clinic, Harrow, UK.

Contributors KMP designed the study, recruited participants, designed and performed the experiments, analysed the data and wrote the manuscript. LG recruited participants and analysed the data. HT analysed the data and wrote the manuscript. SB performed the experiments. MP analysed the data and wrote the manuscript. GSC recruited participants and wrote the manuscript. MK recruited participants. DM-S designed the experiments and provided comments on the manuscript. GPT designed the study and wrote the manuscript. AL designed the study, designed experiments and wrote the manuscript. $A L$ is the guarantor of the study.

Funding This study was funded with a TB Funds Grant TB08/02 from the British Lung Foundation. The funding body was not involved in experimental design, recruitment of participants, experimental work, data analysis, writing the manuscript or manuscript submission.

Competing interests The ESAT-6/CFP-10 ELISpot was commercialised by an Oxford University spin-out company (Oxford Immunotec Ltd, Abingdon, UK) in which Oxford University and Professor Lalvani have a minority share of equity and entitlement to royalties.

Patient consent All patients provided written informed consent using ethically approved Tuberculosis Research Unit research tissue back consent forms.

Ethics approval Ethical approval for this study was obtained from St Mary's REC, 2nd Floor A Block, 50 Eastbourne Terrace, London W2 6LG

(07/H0712/85). Signed informed consent was obtained from all participants.

Provenance and peer review Not commissioned; externally peer reviewed.

Data sharing statement All participants were assigned a unique anonymised study number and all data are stored under this study number. Data sharing: no additional data available.

\section{REFERENCES}

1. HPA. Tuberculosis in the UK. Secondary Tuberculosis in the UK. 2011. http://www.hpa.org.uk/webc/HPAwebFile/HPAweb_C/ 1317131791612

2. ECDC/WHO. Tuberculosis Surveillance in Europe Secondary Tuberculosis Surveillance in Europe. 2009. http://ecdc.europa.eu/en/ publications/Publications/1103_TB_SUR_2009.pdf

3. Akolo C, Adetifa I, Shepperd S, et al. Treatment of latent tuberculosis infection in HIV infected persons. Cochrane Database Syst Rev 2010 (1):CD000171.

4. Diedrich CR, Flynn JL. HIV-1/mycobacterium tuberculosis coinfection immunology: how does HIV-1 exacerbate tuberculosis? Infect Immun 2011;79:1407-17.

5. Thwaites GE, Duc Bang N, Huy Dung N, et al. The influence of HIV infection on clinical presentation, response to treatment, and outcome in adults with tuberculous meningitis. $J$ Infect Dis 2005;192:2134-41.

6. Gonzalez OY, Adams G, Teeter LD, et al. Extra-pulmonary manifestations in a large metropolitan area with a low incidence of tuberculosis. Int J Tuberc Lung Dis 2003;7:1178-85.

7. Dye $\mathrm{C}$, Williams BG. The population dynamics and control of tuberculosis. Science 2010;328:856-61.

8. Pooran A, Booth $\mathrm{H}$, Miller RF, et al. Different screening strategies (single or dual) for the diagnosis of suspected latent tuberculosis: a cost effectiveness analysis. BMC Pulm Med 2010;10:7.

9. NICE. NICE Clinical Guideline 117. Tuberculosis. Clinical Diagnosis and Management of Tuberculosis, and Measures for Its Prevention and Control. 2011. http://www.nice.org.uk/nicemedia/live/13422/ 53642/53642.pdf

10. Bekker LG, Wood R. The changing natural history of tuberculosis and HIV coinfection in an urban area of hyperendemicity. Clin Infect Dis 2010;50(Suppl 3):S208-14.

11. WHO. TB/HIV Facts Secondary TB/HIV Facts. 2011. http://www.who. int/tb/challenges/hiv/factsheet_hivtb_2011.pdf

12. Sonnenberg $\mathrm{P}$, Glynn JR, Fielding $\bar{K}$, et al. How soon after infection with HIV does the risk of tuberculosis start to increase? A retrospective cohort study in South African gold miners. J Infect Dis 2005;191:150-8.

13. Williams BG, Dye C. Antiretroviral drugs for tuberculosis control in the era of HIV/AIDS. Science 2003;301:1535-7.

14. Sonnenberg P, Murray J, Glynn JR, et al. HIV-1 and recurrence, relapse, and reinfection of tuberculosis after cure: a cohort study in South African mineworkers. Lancet 2001;358:1687-93.

15. Cobelens FG, Egwaga SM, van Ginkel T, et al. Tuberculin skin testing in patients with HIV infection: limited benefit of reduced cutoff values. Clin Infect Dis 2006;43:634-9.

16. Diel R, Goletti D, Ferrara G, et al. Interferon-gamma release assays for the diagnosis of latent Mycobacterium tuberculosis infection: a systematic review and meta-analysis. Eur Respir $J$ 2011;37:88-99.

17. Samandari T, Agizew TB, Nyirenda S, et al. 6-month versus 36month isoniazid preventive treatment for tuberculosis in adults with HIV infection in Botswana: a randomised, double-blind, placebocontrolled trial. Lancet 2011;377:1588-98. 
18. Pozniak AL, Coyne KM, Miller RF, et al. British HIV Association guidelines for the treatment of TB/HIV coinfection 2011. HIV Med 2011;12:517-24.

19. Chapman AL, Munkanta M, Wilkinson KA, et al. Rapid detection of active and latent tuberculosis infection in HIV-positive individuals by enumeration of Mycobacterium tuberculosis-specific T cells. AIDS 2002;16:2285-93.

20. Mutsvangwa J, Millington KA, Chaka $\mathrm{K}$, et al. Identifying recent Mycobacterium tuberculosis transmission in the setting of high HIV and TB burden. Thorax 2010;65:315-20.

21. Dodd PJ, Millington KA, Ghani AC, et al. Interpreting tuberculin skin tests in a population with a high prevalence of HIV, tuberculosis, and nonspecific tuberculin sensitivity. Am J Epidemiol 2010;171:1037-45.

22. Millet JP, Orcau A, de Olalla PG, et al. Tuberculosis recurrence and its associated risk factors among successfully treated patients. $J$ Epidemiol Community Health 2009;63:799-804.

23. Koppaka VR, Harvey E, Mertz B, et al. Risk factors associated with tuberculin skin test positivity among university students and the use of such factors in the development of a targeted screening program. Clin Infect Dis 2003;36:599-607.

24. Brock I, Ruhwald M, Lundgren B, et al. Latent tuberculosis in HIV positive, diagnosed by the $M$. tuberculosis specific interferon-gamma test. Respir Res 2006;7:56.

25. Jones S, de Gijsel D, Wallach FR, et al. Utility of QuantiFERON-TB Gold in-tube testing for latent TB infection in HIV-infected individuals. Int J Tuberc Lung Dis 2007;11:1190-5

26. Jee SH, Golub JE, Jo J, et al. Smoking and risk of tuberculosis incidence, mortality, and recurrence in South Korean men and women. Am J Epidemiol 2009;170:1478-85.

27. Leung CC, Yew WW, Chan CK, et al. Smoking and tuberculosis in Hong Kong. Int J Tuberc Lung Dis 2003;7:980-6.

28. Leung CC, Li T, Lam TH, et al. Smoking and tuberculosis among the elderly in Hong Kong. Am J Respir Crit Care Med 2004;170:1027-33.

29. Altet-Gomez MN, Alcaide J, Godoy P, et al. Clinical and epidemiological aspects of smoking and tuberculosis: a study of 13,038 cases. Int J Tuberc Lung Dis 2005;9:430-6.

30. Ktsanes VK, Williams WL, Boudreaux VV. The cumulative risk of tuberculin skin test conversion for five years of hospital employment. Am J Public Health 1986;76:65-7.

31. Baussano I, Bugiani M, Carosso A, et al. Risk of tuberculin conversion among healthcare workers and the adoption of preventive measures. Occup Environ Med 2007;64:161-6.

32. Baussano I, Nunn P, Williams B, et al. Tuberculosis among health care workers. Emerg Infect Dis 2011;17:488-94.

33. Grimes CZ, Hwang LY, Williams ML, et al. Tuberculosis infection in drug users: interferon-gamma release assay performance. Int $J$ Tuberc Lung Dis 2007;11:1183-9.

34. O'Grady J, Hoelscher M, Atun R, et al. Tuberculosis in prisons in subSaharan Africa-the need for improved health services, surveillance and control. Tuberculosis (Edinb) 2011;91:173-8.
35. Baussano I, Williams BG, Nunn P, et al. Tuberculosis incidence in prisons: a systematic review. PLOS Med 2010;7:e1000381.

36. Dosanjh DP, Hinks TS, Innes JA, et al. Improved diagnostic evaluation of suspected tuberculosis. Ann Intern Med 2008;148:325-36.

37. Pareek M, Watson JP, Ormerod LP, et al. Screening of immigrants in the UK for imported latent tuberculosis: a multicentre cohort study and cost-effectiveness analysis. Lancet Infect Dis 2011;11:435-44.

38. HPA. Diagnosed HIV-Infected Individuals Seen for Care. Survey of Prevalent HIV Infections Diagnosed (SOPHID). Black-African and Black-Caribbean Data Tables. 2011. http://www.hpa.org.uk/web/ HPAwebFile/HPAweb C/1221482345789

39. Selwyn PA, Hartel D, Lewis VA, et al. A prospective study of the risk of tuberculosis among intravenous drug users with human immunodeficiency virus infection. N Engl J Med 1989;320:545-50.

40. Aichelburg MC, Rieger A, Breitenecker F, et al. Detection and prediction of active tuberculosis disease by a whole-blood interferongamma release assay in HIV-1-infected individuals. Clin Infect Dis 2009;48:954-62.

41. Latorre I, Martinez-Lacasa X, Font R, et al. IFN-gamma response on T-cell based assays in HIV-infected patients for detection of tuberculosis infection. BMC Infect Dis 2010;10:348.

42. Stephan C, Wolf T, Goetsch U, et al. Comparing QuantiFERON tuberculosis gold, T-SPOT tuberculosis and tuberculin skin test in HIV-infected individuals from a low prevalence tuberculosis country. AIDS 2008:22:2471-9.

43. Grant AD, Bansi L, Ainsworth J, et al. Tuberculosis among people with HIV infection in the United Kingdom: opportunities for prevention? AIDS 2009;23:2507-15.

44. Karam F, Mbow F, Fletcher H, et al. Sensitivity of IFN-gamma release assay to detect latent tuberculosis infection is retained in HIV-infected patients but dependent on HIV/AIDS progression. PLoS One 2008;3 e1441.

45. Liebeschuetz S, Bamber S, Ewer K, et al. Diagnosis of tuberculosis in South African children with a T-cell-based assay: a prospective cohort study. Lancet 2004;364:2196-203.

46. Mandalakas AM, Hesseling AC, Chegou NN, et al. High level of discordant IGRA results in HIV-infected adults and children. Int $J$ Tuberc Lung Dis 2008;12:417-23.

47. Cattamanchi $A$, Smith $R$, Steingart $K R$, et al. Interferon-gamma release assays for the diagnosis of latent tuberculosis infection in HIV-infected individuals: a systematic review and meta-analysis. Acquir Immune Defic Syndr 2011;56:230-8.

48. Leidl L, Mayanja-Kizza H, Sotgiu G, et al. Relationship of immunodiagnostic assays for tuberculosis and numbers of circulating CD4+ T-cells in HIV infection. Eur Respir J 2010;35:619-26.

49. Clark SA, Martin SL, Pozniak A, et al. Tuberculosis antigenspecific immune responses can be detected using enzyme-linked immunospot technology in human immunodeficiency virus (HIV)-1 patients with advanced disease. Clin Exp Immunol 2007; 150:238-44. 